\title{
MISTEK
}

iv

\section{Compressed Magnetic Flux With Capacitive Load}

Orum M. Shutrer

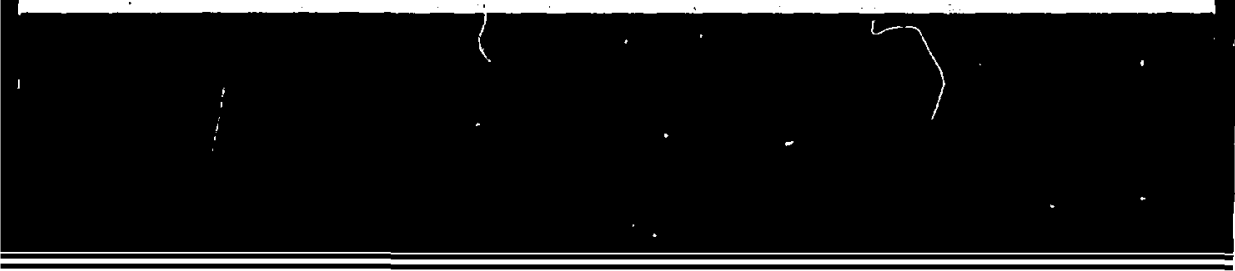

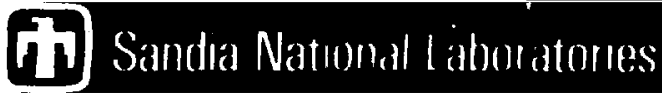


SAND79-2339

Unlimited Release

grinted March 1980
Di atribution

Category uC-20b

\section{COMPRESSED MAGETIC FLUX AMPLIFIER WITH GAPACITIVE LOAD}

Otmar Y. Stuetzer

Energy Subsyotens Division 2165

Sandia Leboretaries

Albuquerque, AM 87185

\section{ABSTRACT}

A firat-order analyois is prenented for conpreosed magnetic flux (GMF) current aplifier working into - lodd with a capecitive component. Since the purpose of the inveatigation was to gain a general underatandisg of the arraugement, a nuber of approximetione and limitations were accepted, The inductance of the traneducer varies with $t$ ine; the inductance/reaiatance/ capacitance (IRC) circuit therefore is paremetric and colutiona are different for the atable regine (high $C$ ), the oncillation ragine (low C), and the transition cave. Solutione and perforsance depend etrongly on circuit boundery conditione, i.e., energisetion of the circuit by either an injected current or by an applied cepacitor crarge. The behavior of current and energy aplification for the varioue cases are discused in detail. A nuber of experiments with anl an devices showd that the firet-order theory presented predicte traneducer performance well in the linear ragine. 


\section{ACKNOWLEDGMENT}

The work was performed at the suggestion of J. B. Gover. J. L. Johnson prepared the experiments. E. C. Cnare and T. J. Tueker contributed greetly to date evaluation. P. C. Reardon of Science Applications, Inc., ehecked our analytic solution by neans of a computer program. 
Introduction

Inductences and Reviatances

The Circuit Equation

Solutions

Discussion

Oecillating Regime

Coment on Applications

Experinent.

Parsmeter Valued

\section{ILLUS TRATIONS}

Figure

1 Schematic of Transducer and Loed

2 Time Depeadence of Hormalized Current and Voltage for Trantition Capacitance $C_{t}$

3 Exmple of Oecillatory Response for Capacitor Charge-Up Initiation

4 Circuit Bhavior for Capacitance Decreased by Factor 10 With Respect to Figure 3

5 Nomalized Voltage and Current Valves at End of CompreatIon $\left(t-t_{c}\right)$ for Curreat Injaction and for Voltage Initiation

6 Meauring Arrengerent with Location of short C1rcuit at Time 21 $t_{c}$ and at Tine $t_{c}+t^{\text {t }}$

7 Shot 2, Conputer Retrieved Digitied Date $(c=0.02$ I) 


\section{ILLUSTRATIONS (cont)}

Eipure

8

9

Shot 7, Computer Retrieved Digitized Data

Pare .

Shot 2, Voltage Acroos Capacitor Taken From Integrated Current Dats

26

\section{TABLES}

Toble

Page

1

Definition

12

2 Solution for Circuit Current I and Capacitor Voltage U

13

3 Expected and Measured Currents

23 
COMPRESSED MAGETIC FLUX AMPLIFIER WITH CAPACITIVE LOAD

Introduction

This investigetion is based on preceding work analyzing the oporation of a conpressed magnetic flux (CMF) traneducer into an inductive-reaitive load. 1 a second-order theory for this conbination ${ }^{2}$ takes into account the variation of okin depth with tine, and flux trapping by wire ahape and by two contact delay phenonena. An attempt to extend this second-order theory directly to the capacitive load case proved analytically unfeasible. We will use the analyeis of Ref 2 only to determine the rather sensitive end values of generator inductance and generator resistance; inductance and resiatance will then be approximated quite accurately by a parabolic function and by a linear function, respectively. A second-order different.al equation resulte wich, for the general ease, has to be conputer-integrated. However, if we 1 imit one resistance or one inductance parameter to apecific values deterwined by the other parameters a very imple analytic solution reault, thich we thall purave. The load reaiatance was selected a the 1 inited parmeter for the derivation; it may be replaced by other resistances or inductances. The 1 imitation introduced is not a severe one for practical cases. 


\section{Inductances and Resietances}

As Figure 1 illuetrates, our arrangenent is a series circuit of inductances ( $L$ ), resistances ( $R$ ), and the load capacitance (C). The inductance and resistance of the generator coil are shorted out progressively, but not completely, by the explosively expanding armature. From Ref 1 we know that the inductance at crowbar time, $t=0$, is the sum of the coil inductance $\mathrm{L}_{0}$ and the load inductance $\mathrm{L}_{\mathrm{L}}$. At end of cont pression, $t=t_{c}$, the inductance has an end value $L_{e}$, which is the oum of load inductance $L_{L}$ and a remant inductance $L_{R}$. The decrease from 1:itial to end inductance is nearly parabolic. Similarly, we have during compreasion a decrease of device resistance from $R_{O}+R_{L}$ to an end resiotance $R_{e}$; this decrease is linear, however.

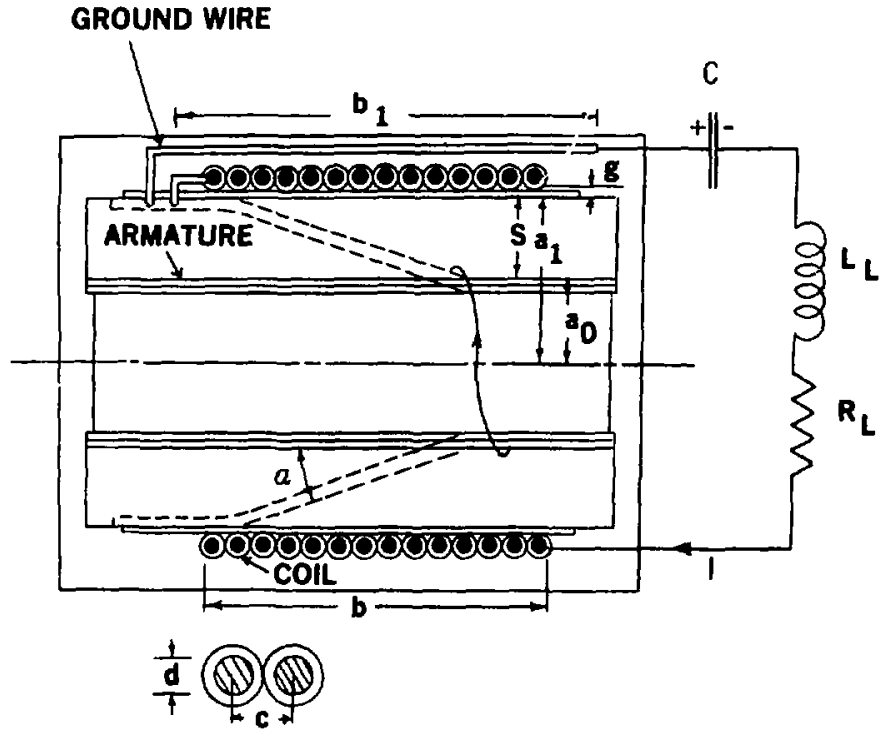

Yigure 1. Schmetic of. Traneducer and Load 
From Eg̣ (14) and (11) of Ref. 1 we obtain the following values for $\mathrm{L}_{\mathrm{e}}$ and $\mathrm{R}_{\mathrm{e}}$ :

$$
\begin{aligned}
& L_{e}=L_{0} \cdot k \cdot \sqrt{\frac{8}{R_{m}}}(1-\Gamma)\left\{T^{*}+\frac{(1-\Gamma)^{2}}{12}\right\}+L_{L} \\
& R_{e}=R_{0} \cdot \frac{1}{1-\Gamma}\left\{T^{*}+\frac{(1-\Gamma)^{2}}{12}\right\}+R_{L} .
\end{aligned}
$$

Here $k$ is a wire thape factor close to unity, $F_{\mathrm{m}}$ is the magnetic Reynolds number for the flux compressor, $\Gamma$ is the slope of the time decrease of the skin layer thickness and has values between 0.4 and 0.6 , and $\tau^{*}$ is the ineulator breakdown delay tine normalized to the conpression time $t_{c}$ and $i s$ of the order of magnitude 0.03 . All the guantities are discussed in Refs. 1 and 2 in much more detail. In practice, $L_{e}$ and $R_{e}$, and with them $L_{L}$ and $R_{L}$, are much amaller than the initial values $L_{0}$ and $\mathbf{R}_{\mathbf{0}}$.

With this, the time functions for inductance and resistance, which show the proper initial values and end values, can be written:

$$
\begin{aligned}
& L(t)=\left(L_{0}+L_{L}\right)\left[1-\frac{t}{t_{c}}\left(1-\sqrt{\frac{L_{e}}{L_{0}+L_{L}}}\right)\right]^{2} \\
& g(t)=\left(R_{0}+R_{L}\right)\left[1-\frac{t}{t_{c}}\left(1-\frac{R_{e}}{R_{0}+R_{L}}\right)\right]
\end{aligned}
$$

for times $0 \leq t \leq t_{c}$.

We now wake the tine parameter for the two equationa identical by stipulating

$$
\sqrt{\frac{L_{e}}{L_{0}+L_{L}}}-\frac{R_{e}}{R_{0}+R_{L}}
$$

or, in practical cases, limiting the load resistance $R_{e}$ to $R_{e}=R_{o} \sqrt{L_{e} / L_{o}}$. Equetion (3) together with $E_{q}(2)$ selecta a value for $R_{L}$, or $R_{0}$, at our option. 
Abbreviating: $\mathrm{L}_{\mathrm{O}}+\mathrm{L}_{\mathrm{L}}=\mathrm{L}_{1}$

$$
R_{0}+R_{L}=R_{L}
$$

and introducing a time parameter $X$ and a compression parameter $\alpha$ by writing

$$
\begin{aligned}
& x=1-\alpha \frac{t}{t_{c}} \\
& \alpha=1-\sqrt{\frac{L_{e}}{L_{0}+L_{L}}},
\end{aligned}
$$

we can now conveniently write for the time functions:

$$
\begin{aligned}
L(t) & =\mathrm{L}_{1} \mathrm{X}^{2}, \\
\mathrm{R}(\mathrm{t}) & =\mathrm{R}_{1} \mathrm{X}, \\
I & \geq \mathrm{X} \geq 1-\alpha .
\end{aligned}
$$

The phyoical meaning of our mathematical manipuiations is trat we have defined a new compressor coil, longer by a factor of about $1 / \alpha$, the entire length of which we do not completely use. This way, the proper inductance $L_{e}$ and resiatance $R_{e}$ stay in the circuit.

\section{The Circuit Equation}

All the voltages in the circuit of Figure 1 nut add up to the voltage $U_{0}$ originally applied acrose the capacitor C (if any); thus, we have for the current $I$ in the tranaducer

$$
\frac{d}{d t}(L I)+R I+\frac{1}{c} \int I d t-U_{0} .
$$


We introduce the flux linkage $\phi=$ LI and differentiate:

$$
\frac{d^{2}}{d t^{2}} \phi+\frac{d}{d t}\left(\frac{R}{L} \phi\right)+\frac{1}{L C} \phi=0 .
$$

For practical use we will consider two boundary conditions for circuit $\mathrm{Eq}(7)$ :

1. At tine $t=0$, an injected current $I_{0}$ flow in the eyoten but there is no voltage acros the capacitor $\left(\mathrm{U}_{0} \approx 0\right)$

2. At tine $t=0$, a voltage $U_{0}$ existo over the capacitor $c$ but no current ia flowing $\left(I_{0}=0\right)$.

We change the variable $t$ to the variable $X$ of Eq (5), with $\mathrm{dX}=$ $-\left(\alpha / t_{c}\right) d t$, and introduce the values for $R$ and I fron Eq $(6)$. With the prime representing differentiation after $X$, we obtain

$$
x^{2} \phi^{\prime \prime}-\frac{R_{1} t_{c}}{\alpha_{L_{1}}} x^{\prime} \phi+\left(\frac{R_{1} t_{c}}{\alpha_{L_{1}}}+\frac{t_{c}^{2}}{\alpha_{L} L_{1} c}\right) \phi=0 .
$$

This is an Euler equation, and the solutions are readily available in the literature. ${ }^{3}$ The two arbitrery constants occurring in the solution of a second order differential equation have to je determinad from the boundary conditione ( 1 or 2 ) above. The lgebra for thie deteraination, while otraightforward, is quite lengthy and will not be detailed here.

To ellow the solution to be expresed comoniently, we ohall define a number of abbrevieticr. in Table 1 , which al wo contains a repetition of former eseantial defünitione. 
Table 1

Definitions

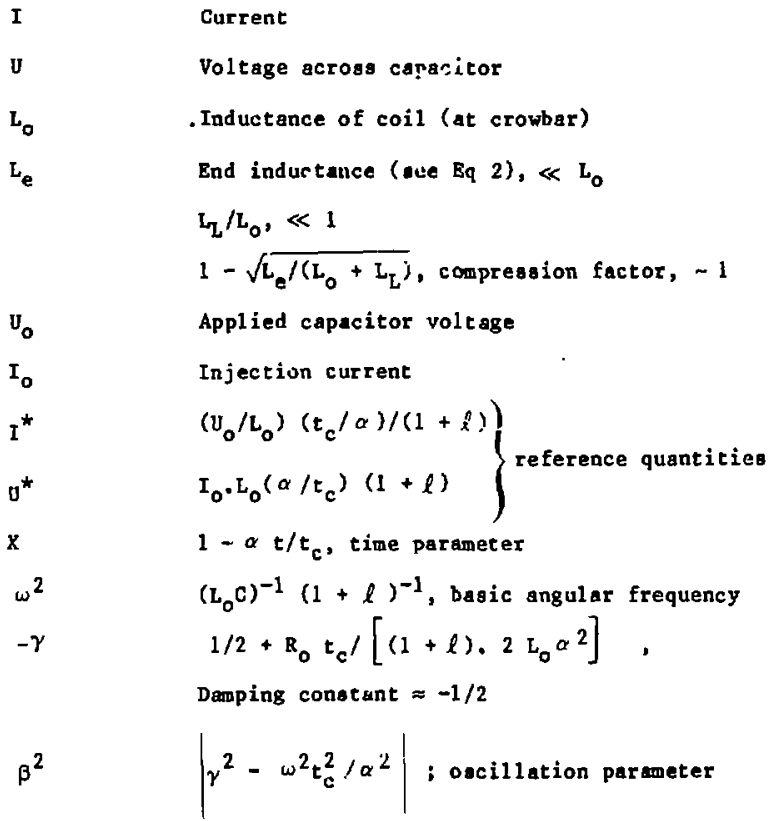

\section{Solution.}

The solutions for circuit current I and capacitor voltage $U_{\text {, }}$ normalized to the appropriate circuit dependent conetante from rable 1 , are 1 isted in Table 2. The dowinant factora are $x^{-\gamma}$ for the voltage rise with time and $x^{-\gamma-1}$ for the current riee with tine $t$, For low 
circuits, these factors behave as

$$
1 / \sqrt{1-\alpha t / t_{c}} \text { or } \quad 1 / \sqrt{1-\alpha t^{3} t_{c}} \text {, }
$$

respectively. At end of compression, $t \rightarrow t_{c}$, the values increase rapidly. The equations are not valid for $t>t_{c}$.

Table 2

Solutions for Circuit Current I and Capacit's Voltage $t$

\section{STABLE CASE A}

$Y>\omega t c / a$

(a) Injected Current Io

$$
\begin{aligned}
& \frac{I}{I}_{a}=\left[\begin{array}{c}
x^{\beta}+x^{-\beta} \\
-\frac{y}{\beta}\left(x^{\beta}-x^{-\beta}\right)
\end{array}\right] \quad x^{-\gamma-1}[1-\gamma \ln x] \quad x^{-\gamma-1}\left[\begin{array}{c}
\cos (\beta \ln x) \\
-\gamma \sin (\theta \ln x)
\end{array}\right] \quad 2-1 \\
& \frac{x^{-\gamma}}{2} \frac{{ }^{2} t_{c}^{2}}{\alpha^{2} \beta}\left[x^{\beta}-x^{-\beta}\right] \quad x^{-\gamma} \cdot \gamma^{2} \ln x \quad x^{-\gamma} \frac{3^{2} t_{c}^{2}}{\alpha^{2} \beta} \sin (\beta \ln x) \quad T 2-2
\end{aligned}
$$

(b) Applled voltage $v_{0}$

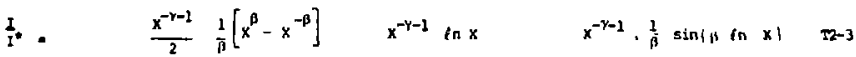

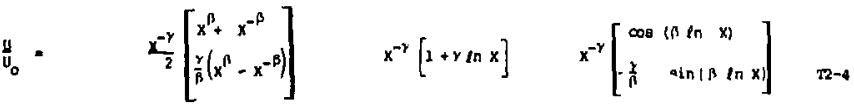


For very high capacitances and low resistances, the current rises approximately as $x^{-2}$. This followg from Eq T2-1 Case $A$, in Table 2 for $C$ $\infty$, or $\beta \rightarrow \gamma$, as well as from direct integration of the now simple Eq (7). Wich decreasing values of $C$, the current rise becones more 1 ike $x^{-3 / 2}$. The device is stable.

Decrease of the capacitance c leads to the boundary of the stability region. The tranaition case is characterized by $w t_{c}=\gamma_{\alpha}$, or a transition capacitance

$$
c=\frac{t_{c}^{2}}{\alpha^{2}\left(L_{0}+L_{L}\right)\left[\frac{1}{2}-\frac{R_{0} t_{c}}{2 L_{0}} \cdot\left(1+\frac{1}{(1+l)} \cdot \frac{1}{\alpha^{2}}\right]^{2}\right.} .
$$

For low resistance we have $C_{t} \approx 4 t_{c}^{2} / L_{0}$.

In Figure 2 solutions for the transicion case (Table $2, B$ ) have been plotted for a set of parameters occurring in practice. The absci:sa is the normalized compression time, $i / t_{c}$. For current injection (Case $a$ ), che current riaes to about 40 times the original value $I_{0}$; a (negative) voltage builds up on the capacitor, first linearly, then faster. For initiation by appilied voltage $v_{0}$ (Gese b), the voltage drops to about twothirds, wile a firot slobly, then fast rising current builde up in the eircuit.

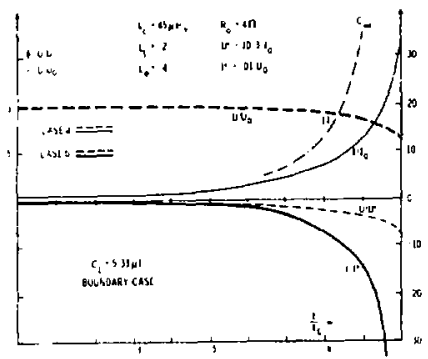

Pigure 2. Time Dependence of Normalized Current and Voltage for Tranaition Capacitance $C_{t}$ 
If $C$ is larger than the critical value $C_{t}$, current changes are higher in absolute values, voltage cianges are lower. For infinftely large $C$, (and $R_{0}=0$ ), the naximum posaible current increase resuita; it is indicated in Figure 2. $U$ is identically zero in this case, of course. The critical capacicance $C_{t}$ decreases wich decreasing losses according to Eq. (9).

When $c$ becomes amaller than $C_{t}$, currents and voltages start reversing during conpression; finally, oscillations develop. An exemple is shown in Figure 3 for a capacitance of about $1 / 100$ of $C_{t}$, and for case $b$, energization through capacitor charging. Current and voltage drop into a phase shift of $\pi / 2$; whenever one has an extreme value, the other one reveraes.

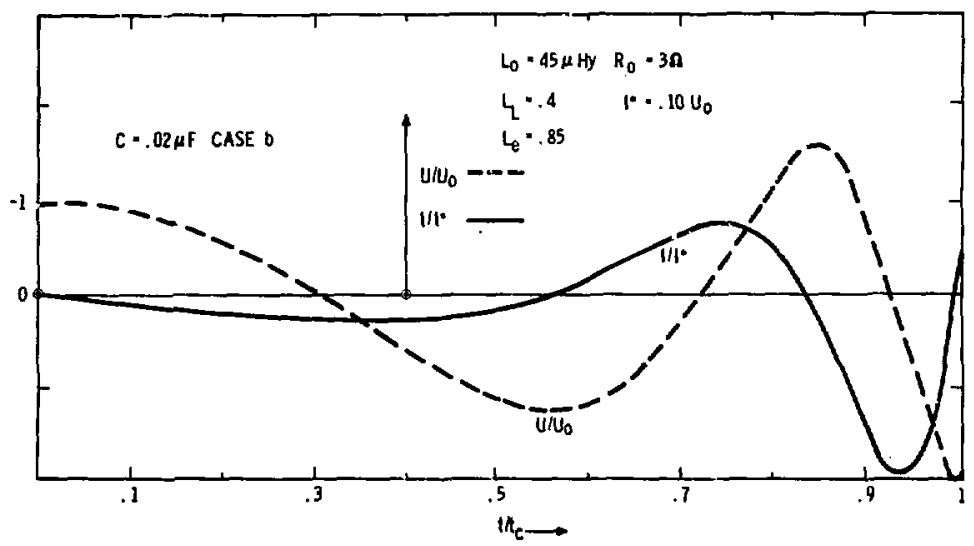

Figure 3. Exeple of Oecillatory Response for Capecitor Cherge-Up Initiation

In Pigure 4 the capacitance is decreased by another factor of 10: wore oscillation pariod ar in evidence. (Their number is proportional 
to $1 / \sqrt{\mathrm{C}}$, but depends sonerhat on the loss revistance $\mathrm{R}_{\mathrm{o}}$ ). We wee that the voltage maxima have about the ane value as in Figure 3 . The current is decreased, however, as the lorrer capacitance neans a higher circuit impedance. The voltage swings increase alightly towards the end of compression, indicating an ineresse in the energy $\left(\mathrm{Cu}^{2} / 2\right)$. This energy amplification is due to our sasuption of $R_{0}=3 \Omega$. For $R=12 \Omega$, the voltage extrema would decrease markedly towards the end. R has little influence on the time position of the maxima or zeron.

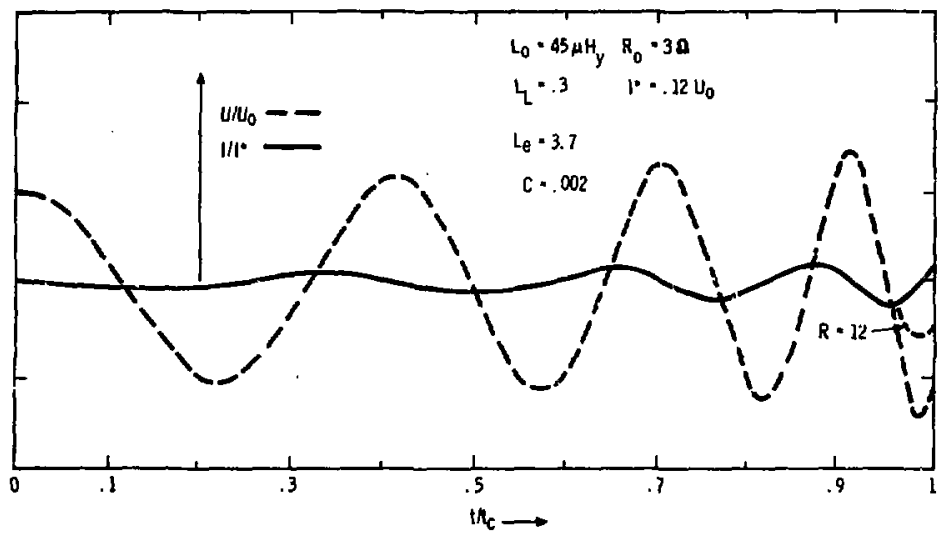

Figure 4. Circuit Behavior for Capacitance Decreased by Factor 10 With Reapect to Figure 3

The periods of the output decrease coward the end of compresaion as the inductance decreases. The device delivers " "chirp pulse". Increase of the load inductance $I_{2}$ noves the time curves to the right, as expectsd. After $t=t_{c}$, no additional energy is furniohed to the circuit, It ringa out, firat with inductance $L_{e}$, and after $a t$ ine $\tau^{\star} t_{c}$ with Inductance $L_{L}$.

If the mathematically simplifying condition ( 3 ) ia dropped, $R_{L}$ enters the analysid as an additional free parmeter. Circuit liq (7) becases a necond order hypergeometric differential equation which can only be computer integrated. P. C. Reardon has performed the integration. 4 The deviations fro our approxiation are onall for factors of 2 or 3 in $\mathrm{R}_{\mathrm{L}}$. 16 
Our olution is therefore certainly very sitable for a general aseasent of device behavior.

\section{Discussicn}

The capacitively loaded CMF aplifier will now be discussed nore generally with the help of Figure 5 in wich the end amplification ra: $: 2$ (i.e., the valuee predicted analytically frou Table 2) at time $t_{c}$ are plotted ve decreating capacitance $c$ for $\mathrm{L}_{0}=65 \mu \mathrm{Hy}, \mathrm{L}_{\mathrm{L}}=0.3, \mathrm{~L}_{e}=0.6$, and $R_{0}=3 \mu$. The nomalization parmeters for this case have the values $U^{*}=14.8 \mathrm{I}_{0}$ and $\mathrm{I}^{*}=0.07 \mathrm{U}_{0}$. The transition capacitance $\mathrm{C}_{t}=2 \mu \mathrm{F}$ is indicated in the graph (lover left oide).

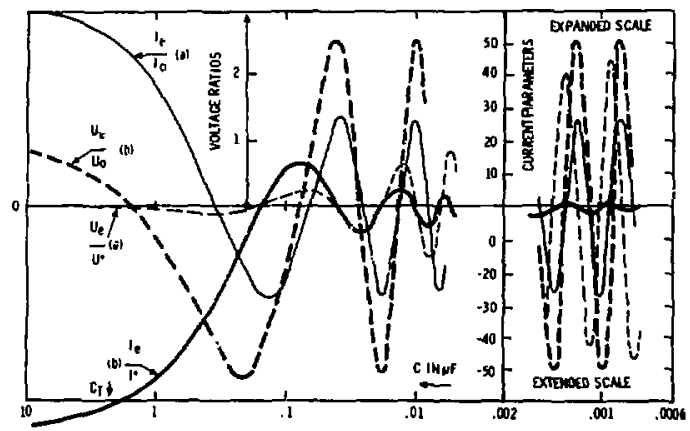

Tigure 5. Normalized Voltage and Current Values at End of Compreasion ( $t-t_{f}$ ) for Current Injection (thin curves) and for Voltage Initiation (thick curves)

We see that at the end of compreseion, currente and volteges fluctuate between woxime and ainima, so is to be expected for a faily of oscillating circuits. There is $990^{\circ}$ phese shift betwen thes; this is a direct effect of the $90^{\circ}$ ohift $r, 1$ the time axis discused above. 
Case a: for injected currente $I_{0}$, the end currente reach quite high valued for large load capacitancea $C$ (Regime $A$, Bigure 5 ). In the oscillating regime, the current maxime and minima are lower and independent of $\mathrm{C}$. The maximum voltages increase with decreasing $C$.

Case b: for initiation of the syotem by a voltage $U_{0}$ (or charge $\mathrm{Cu}_{0}$ ), the end voltage after compression will be omaller than $v_{0}$ in Regime A. In the oscillating regime, the voltage extremes are independent of $C$, and, in our example, about 2.5 times the applied voltage. The current maxima decrease with decreasing $c$,

This somewhat involved behavior becomes understandable, if we look at the energy amplification $\eta$ of the Eranaducer. At $t=0$, the energy furnished is $\left(L_{0}+L_{L}\right) I_{0} / 2$ for injected currenta and $\mathrm{CU}_{0} 2 / 2$ for voltage initiation. The output energy at $t=t_{c}$ is partly stored in the load inductance $\mathrm{L}_{e}$ and partly in the rapacitance $C$. The part stored in the nonlogd portion of the and inductance $l_{e}$ (first form of $\mathrm{Eq}(1 \mathrm{a})$ ) is inaccessible to us but will be considered here. For injected currenta the output energy is

$$
I_{e} I_{e}{ }^{2 / 2}+C U_{e}{ }^{2} / 2=L_{e}\left(I_{e} / I_{0}\right)^{2} I_{o}^{2} / 2+c\left(U_{e} / U^{\star}\right)^{2} \cdot U^{\star 2} / 2 ;
$$

replacing $U^{*}$ from Table 1 , we find

$$
\eta_{a}=\frac{I_{e}}{L_{0}+L_{L}} \cdot\left(\frac{I_{e}}{\bar{I}_{0}}\right)^{2}+\frac{\alpha^{2}}{t_{c}{ }^{2}}\left(L_{0}+L_{L}\right) c\left(\frac{U_{e}}{U^{*}}\right)^{2} .
$$

Similery, for injected currents:

$$
\eta_{b}=\frac{t_{c}{ }^{2}}{\alpha^{2}} \frac{I_{e}}{L_{o}+L_{L}} \cdot \frac{1}{c}\left(\frac{I_{e}}{L^{4}}\right)^{2}+\frac{U_{e}^{2}}{U_{o}^{2}} \text {. }
$$




\section{Oscillating Regine}

Takiug the value of $I_{e} / I_{0}, U_{e} / U^{*}$, etc, from figure 5 , and inserting then inco $\mathrm{Eq}(10)$, we find that within our approxixation and $b$ are about equal and about constant. This is not ourpriaing; circuita with relatively lov lases should behave that way after a nuber of cycles. The energy, wile building up, fluctares from inductence to capacitance and back. If we look now at the capaciter values where $I_{e} / I_{0}$ is zero, i.e., all end energy is in the capacitor, the product $c\left(U_{e} / u^{*}\right)^{2}$ should be conatant; the maxima and minine of $v_{e}$ should therefore vary with $1 / \sqrt{\mathrm{c}}$. Correspondingly, for injected currents the quotient $\left(\tau_{e} / I^{*}\right)^{2} / C$ should bo conatant for the current axima, which then vill vary ad $\sqrt{\mathrm{C} \text {. Figure } 5}$ thow that both conclusions are approximately correct.

In the oscillating regime, the values for energy aplification $\eta_{a}$ and $\eta_{b}$ are about 6.25 for the case plotted in Figure 5, there a renistance $R_{0}=3 \Omega$ was chowen. For better transducers, if they cari be produced, higher amplification are predicted. (If $R_{0}$ mere $1 \Omega$ in Figure 5, we would expect a nine-fold energy gain.)

\section{Stable gegime}

Figure 5 show clearly, that for current injection, the current aplification is larger by about factor 2 than the vaxinu current aplification in the oscillating regine. According to Eq (100), the energy gain is therefore much larger. For very high capacitance $C$, the current. aplificetione epproach those for a purely inductive-resiotive syotan, es trented in Ref. 1. Bnersy aplification, therefore, decreases from atuble to oscillating regine. The main reason for this is that current and therefore magnetic field reverse during comprestion (Figure 3). Mile the field is in the neighborhood of zero, the mechanomagnetic tranaduction machanian doas not operace. A contributing factor is that in certain configuration,, due to faster time variations, the akin effect lonses rige. 
For initiation by a capecitor voltage, the aplification in the atable regive is lower than for the oscillating regime (Figure 5). This is due to the fact that the magnetic field starts at zero at the beginning of coapression and is being eatabliahed quite gradually (Figure 2). For large cr.pacitances the capacitor still holds energy at $t=t_{c}$, which would be needed to gennate the magnetic working field.

\section{Comments on Applications}

The preceding discusaion described the physice of the device. For actual applicationa, a number of additional points must be considered.

It was evident from our derivation that we cannot take energy out of the tctal inductance $\mathrm{L}_{e}$; only the losd part $\mathrm{L}_{\mathrm{L}}$ is accessible to us. Thit aceni to make energy from capacitive atorage in $C$ preferable, but in practice, every capacitor has a series inductance and what is accesaible is always an LRC combination. This reduces the energy gain.

It nay appeat from the above discussion that from the energy gain point of view, the voltage $U_{0}$ initiated arrangement is inferior; in the oscillating regime it is not better than the injection current initiated transducer, and in the high $C$ regime it is much worae. Actually, by introduction of a witch voltage initiation can be transformed into injected current: we charge up the capecitor, short the circuit, and after a quarter period of oscillation there will be maximum current in the coil and no voltage acrose the capacitor. At this moment we atart field compreation.

Experiment:

Nine experinente were performed with laboretory test unit (LTU) transducer: described in Ref. 1. The aggravating probleme caused by inoufficiently precies machining of coilo, ematures, and exploaive 
ticks discused in Ref. 1 were in full evidence. Conoiderable data scatter and an occseional discontinuity had to be accepted.

All shota were performed with capacitor charge initiation, whish is experimentally much inpler than current injection.

\section{Parameter Valued}

The effective measuring circuit is hown in Figure 6 . Inductance $L_{C}$ and resistance $R_{C}$ of the capacitor package $C$ is not negligible in our experiments. $\mathrm{L}_{\mathrm{Y}}$ and $\mathrm{R}_{\mathrm{Y}}$ are values belonging to the measurement circuit and the cur current gauge, and are of the order $50 \mathrm{nH}$ and $30 \mathrm{~m} \Omega$, respectively. $L_{R}$ and $R_{R}$ are the inductance and resistance remaining in the coil at end of compression; according to Ref. I we expect contributions of about $0.4 \mu \mathrm{H}$ and $36 \mathrm{~m} \Omega$.

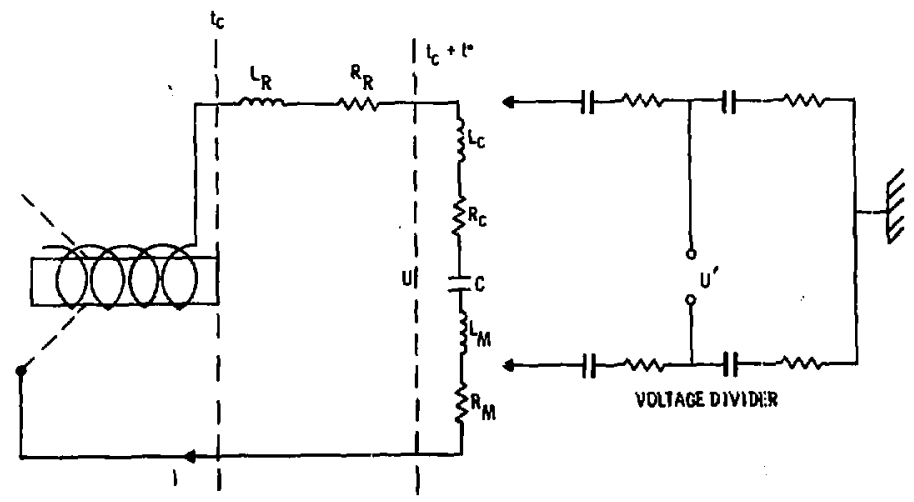

Pigure 6. Keasuring Arrangenent With Logation of Short Circuit at Tine $t_{c}$ and at Tine $t_{c}+t^{*}$

The circuit rings out after the end of conpression; this vill be more fully diecused later. The ringing frequency it ficet deterained by $\mathrm{C}$ and all the inductances and realetances otill in the circuit after compreasion. After a tiee $t^{*}$, about 200 Ho in our cane, $L_{R}$ and $R_{R}$ have disappeared and the circuit ansuna comevthet higher frequency. For mall $L_{L}$, the effect is cell observable and is alrect proof of tha 
existence of $\mathrm{L}_{R}$, the remanent inductance. The ring-out gives us the opportunity to determine inductances and resistances in the circuit by measuring frequency and decrement. In practice, this is reasonably accurate onty for the end of the ringout, permitting us to measure $L_{L}=L_{G}$ $+I_{M}$ and $R_{L}-R_{C}+R_{M}$. The end-compression values $L_{e}$ and $R_{e}$ can then be detemined by adding $L_{R}$ and $R_{R}$ froo reference 1 , or by using $E_{q}$ (1).

The initial inductance $L_{0}$ at crowbar was $45 \mathrm{H}$ for the experimentel transducers. This gives us $L_{1}=L_{n}+L_{L}$, wich we need for detemining the parameters in Table 1.

We have determined $R_{e}$ experimeatally, so the initial circuit resiatance $k_{0}+R_{L}$ is no longer free but is determined by Eq ( 3 ). This causes errns at the beginniag of compression but guasantees proper pormerer values at the end, where it is importanc.

The capacitances used and the inductances and resiatances determined as described are listed in the left column of table 3 . With then, and Table 1, we can check our theory, using the equations of Table 2.

\section{Current Meaurements}

Current vo time, predicted by Eq (3) of Table 1, was measured by a calibrated current viewing transformer. Bxcellent agreement was found both for shape and amplitude.

An an exaple, Figure 7 show the current trace for Shot 2 (see Table 3) as plotted by computer from digitized data. The load capacitor was 0.02 F. Except for sign reversal, the thepe of the curve is the one predicted by Figure 3 (for alightly different otarting resistance). Peak values are well within 107 of prediction. 


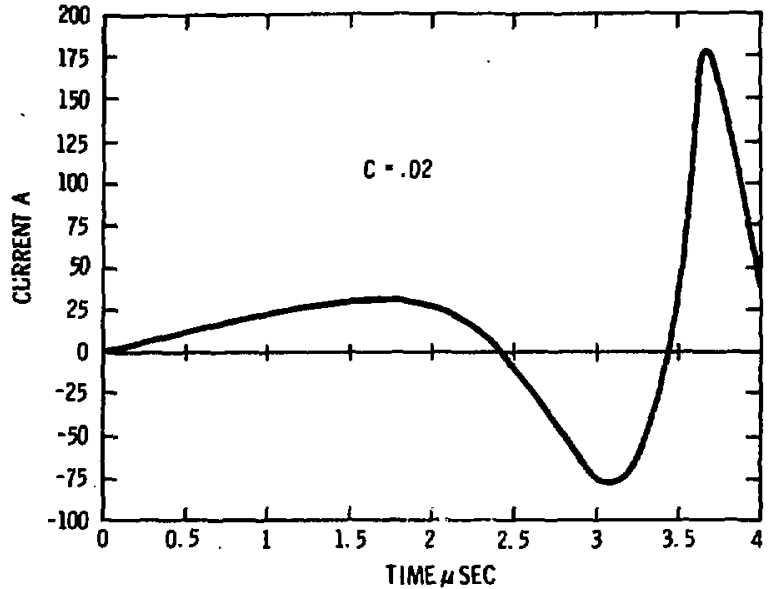

Figure 7. Shot 2, Conputer Retrieved Digitised Date (c $=0.02 \mu \%)$

Table 3

Bxpected and kisaured Currents

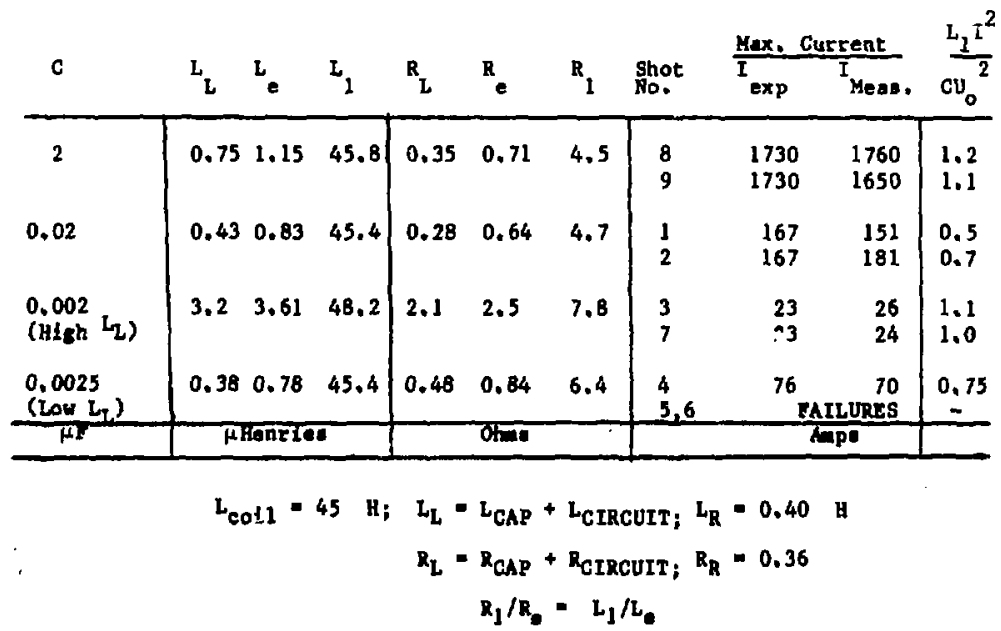


A current measurement for amal ler capacitive load $\mathrm{c}=0.002 \mu \mathrm{F}$, (Shot 7) is plotted in Figure 8 on an extended time ecule. The corpreasion time $t_{c}=4.1 \mu$ is indicated. We see that current is flowing before the device crowbars. This phenomenon is related to preamplification as discussed in Ref, 2. Before crowbar, the coil-armature combination is a capecitance $c^{\prime}$ cherged to voltage $U_{0}$. Ao the armature expands, the capacitance $c^{\prime}$ decreases, inducing a current $U_{0} d c^{\prime} / d t$ into the parametric aystem and cauning preringing.

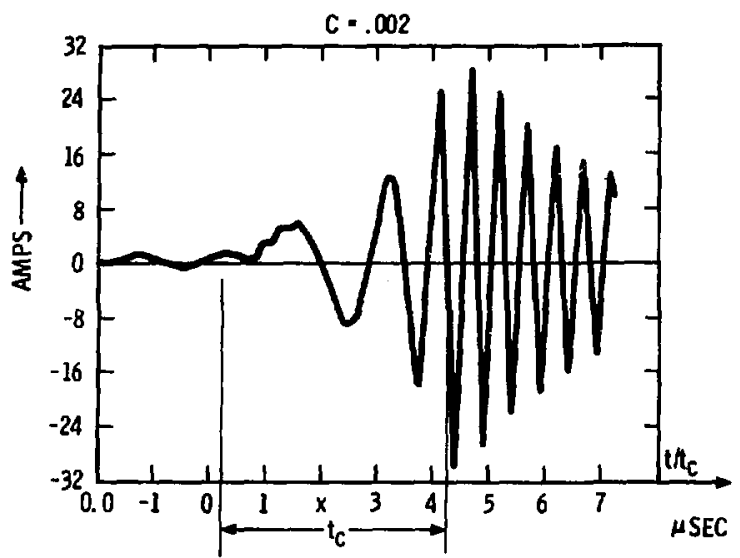

Figure 8. Shot 7, Computer Retrieved Digitized Data

During the firat $c y c 1$ of compression we notice clocking. After compession the circuit rings out, a diacusaed. We observe a relatively fact decay, due to the high renistance $(>2 \Omega)$ remaining in the circuit. The firat cycle is about $6 \%$ longer then the ubsequent ones due to the presence of the inductence $L_{R}$ during this time; this egrees with the theoretically predicted percentage $L_{R} / 2 L_{L}$.

Expeted and mesured currents for our experiments are 1 isted in Table 3. 


\section{Voltare heasuresenta}

At tempte to measure the voltage across the capacitor with a frequency independent, extrenely high inpedence voltage divider (Figure 6) ran into difficulties. The theory predicta the voltage on the capacitor; what we can meare is the velue acrose the combination $L_{C}, R_{C}$, and $c$, Circuit analyai desends a correctinn factor

$$
U^{\prime} / U=\sqrt{\left(1-\omega^{2} L_{c} c\right)^{2}+\omega^{2} R_{c}{ }^{2} c^{2}}
$$

where $\omega$ is the angular ringing frequency and the wole factor is typically between 0.7 and 0.9 . This correction factor wes not enough for higher frequency devices: there are additional parallel capacitances and aeries inductences in the circuit wich complicate the eituation. Occasional breakdown and charge shifts occurred in the voltage measuring circuit. Otherwise, the messurewents showed the expected features.

The current measurements were very good, so the voltage across $C$ could be detemined by conputer integration from I:

$$
v-u_{0}=\left(\int I d t\right) / C .
$$

Excellent agreement with theoretical predictions was obtained by this method. An exmple is shown for shot 2 in Figure 9, where the current values of Figure 7 were used. We see that the result compares very whl with the voltage curve predicted in Figure 3 . 
81447912

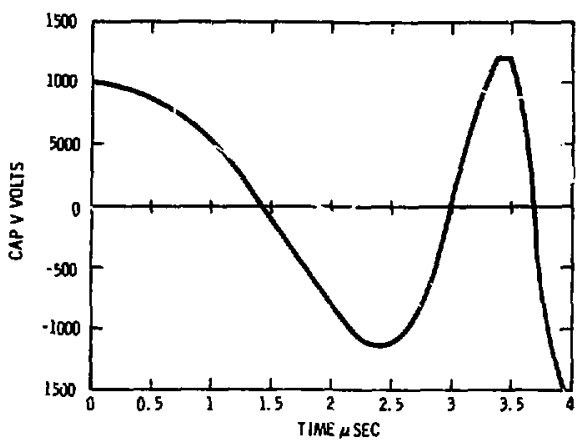

Figure 9. Shot 2, Voltage Across Capacitor Taken From Integrated Current Date

\section{Clocking Renonance}

Shots 5 and 6 are marked as failures in Table 3. Tor these shots, a low inductance load capacitor was chosen. It developed that the capacitor resonance was very close to the clocking frequency. Strong oscillations, high current and voltage amplitudes, and current/voltage jumpo occurred. In retroopect, it was recognized that the circuit behavior had to be very complex. Thile this effect wes not pursued further, it could be useful for generation of very high frequencied ( 20 to $50 \mathrm{kHz}$ ) at good power aplification.

\section{Energy Applification}

For the reported experinente the energy amplification wee rarely above 1.1 to 1.2, and often below unity. In Table 3, last cpolumn, we conpare the end enersy occurring at nexlaun current in the inductive part of the load $L_{L}$, wich is $\left(L_{L} I^{2}\right) / 2$, to the inveated energy $\left(\mathrm{CU}_{0}^{2}\right) / 2$. For the energy otored in the capacitor, very aimilar renulto are obteined. The low veluee are due to the high reslotences end load Inductences in our experimentel ceries, and do not signify that the eystem le uselese for enersy aplification. It neane, however, that for wany applicatione the load will heve to be designed carefully. 
Conclueion

The anslyais presented describes the linear operation of a compresed aagnetic flux eaergy traniducer into general LRC load. A number of approximations and implifications had to be used. The resiatance of the systen is taken to vary linearly with time after crowbr, and inductence ia deacribed by a parabolic tine functiod ( $\mathrm{sq}(1))$. Conoiderable inductance and reaietance renain in the coil-arwature oyatem after corpression ends, anslyzed in previous work. Correction. for inaulatpr breakdown delay, field inertia, and skin depth influence are contained i the end values (Eq (1)).

Analyai was found to be feasible only if resistances and inductances are 1 irited by a mutual relationohip (Bq (3)). This limitation does not atrongly effect the resulte, eapecially if the important values at the end of compresion are correctly preserved; we did this for our experiments.

Solution of the circuit equation for qur parametric circuit distinguishes three cases, stable regime A, an oacillating regime $C$, and a tranuition case $B$ (aee Table 3 ). The oolutions are different for different aethods of energizction: injected current and charged up load capecitor.

A number of experimenta with availablel teat units proved that the theory presented deecribea the arrangement vell. We therefore have a basia to analyze device performance for opecific applicationa. 


\section{Reference.}

1J. E. Gover, O. M. Stuetzer, and J. L. Johneon, Sall Helical Flux Compression Auplifiexs, Proceedings of Second International Conference on Vegagaus Fields (1979). In print.

${ }^{2}$ o. M. Stuetzer, "Theory of Suall helical Magnetic Flux Compreasion Aplifiers," SAND79-1075 (Albuquerque: Sandia Laboratoriea, Sept 1979).

3E. Kanke, Differential Equationa, Akadenieche Verlagsgesellschaft, Leiprig, 194a, p 341.

${ }^{4} P$. C. Reardon, Coil CHF Goneratore with an LRC Load, Internal Report, 11203 rd NW, Albuquerque, IM (Science Applications, Inc., Auguat 1979). 